\title{
Transient myeloproliferative disorder as the presenting feature for mosaic trisomy 21
}

\author{
Nicole Baca, ${ }^{1,2}$ Pedro A. Sanchez-Lara, ${ }^{1,2}$ Rhona Schreck, ${ }^{1,2}$ Celeste C. Eno, ${ }^{1}$ \\ and Fataneh Majlessipour ${ }^{1,2}$ \\ ${ }^{1}$ Cedars-Sinai Medical Center, Los Angeles, California 90048, USA; ${ }^{2}$ David Geffen School of Medicine, \\ University of California, Los Angeles, Los Angeles, California 90027, USA
}

Abstract Trisomy 21 is a common congenital disorder with well-documented clinical manifestations, including an increased risk for the transient myeloproliferative disorder as a neonate and leukemia in childhood and adolescence. Transient myeloproliferative disorder is only known to occur in hematopoietic cells with trisomy 21. Children with mosaic trisomy 21 also have a risk for hematological malignancies. We present a nondysmorphic neonate, with a negative noninvasive prenatal screening of maternal blood for trisomy 21 , who came to medical attention because of ruddy skin. He was found to have mild polycythemia, thrombocytopenia, and developed peripheral blasts. His clinical presentation was consistent with transient myeloproliferative disorder, which is only seen with trisomy 21. Cytogenetic studies of peripheral blood are positive for mosaic trisomy 21 .

Corresponding author: nicole.baca@cshs.org

(c) 2021 Baca et al. This article is distributed under the terms of the Creative Commons Attribution-NonCommercial License, which permits reuse and redistribution, except for commercial purposes, provided that the original author and source are credited.

Ontology terms: extramedullary hematopoiesis; hematological neoplasm

Published by Cold Spring Harbor Laboratory Press

doi:10.1101/mcs.a006126

\section{CLINICAL PRESENTATION AND FAMILY HISTORY}

Although trisomy 21 is reliably detected by modern screening and diagnostic platforms, there are limitations to all tests. Therefore, ensuring a high level of suspicion despite a negative screening test is imperative in clinical practice. We present a term nondysmorphic neonate with thrombocytopenia, polycythemia, and low levels of circulating blasts raising concern for a myeloproliferative disorder, which spontaneously resolved, and discuss the considerations and relevance of this finding to mosaic trisomy 21.

A 1-d-old nondysmorphic term male was evaluated in the newborn nursery because of a ruddy skin complexion. He was born at $39 \mathrm{wk} 2 \mathrm{~d}$ to a $37-y r-o l d$ mother by vaginal delivery with an unremarkable pregnancy, with reportedly normal cell-free DNA screening (noninvasive prenatal screening [NIPS]) and family history. His initial complete blood count (CBC) with differential showed $18.85 \times 10^{3} / \mu \mathrm{L}$ whole blood count (WBC) (reference range 8.04-15.40 $\times$ $10^{3} / \mu \mathrm{L}$ ); absolute polymorphonuclear cells $11.20 \times 10^{3} / \mu \mathrm{L}$ (reference range $5-28 \times 10^{3} / \mu \mathrm{L}$ ); lymphocytes $4.22 \times 10^{3} / \mu \mathrm{L}$ (reference range $2-11.5 \times 10^{3} / \mu \mathrm{L}$ ); monocytes $2 \times 10^{3} / \mu \mathrm{L}$ (reference range $<2.5 \times 10^{3} / \mu \mathrm{L}$ ); eosinophils $0.57 \times 10^{3} / \mu \mathrm{L}$ (reference range $0.1-2 \times 10^{3} / \mu \mathrm{L}$ ); basophils $0.2 \times 10^{3} / \mu \mathrm{L}$ (reference range $<0.4 \times 10^{3} / \mu \mathrm{L}$ ); immature granulocytes $0.66 \times 10^{3} / \mu \mathrm{L}$ (reference range $0-0.1 \times 10^{3} / \mu \mathrm{L}$ ); no blasts; hemoglobin $20.8 \mathrm{~g} / \mathrm{dL}$ (reference range 13.9$19.1 \mathrm{~g} / \mathrm{dL}$ ); and platelets $90 \times 10^{3} / \mathrm{\mu L}$ (reference range 150-350 $\times 10^{3} / \mu \mathrm{L}$ ). His platelet count was as low as $44,000 / \mu \mathrm{L}$ for which he received random-donor platelet transfusion and intravenous IgG on day of life 4 . He had a good response 1-h post-transfusion, with a platelet count recovery to $139,00 / \mu \mathrm{L}$; however, on the following day, his platelets fell to 
COLD SPRING HARBOR Molecular Case Studies
Mosaic trisomy 21 presenting as TMD
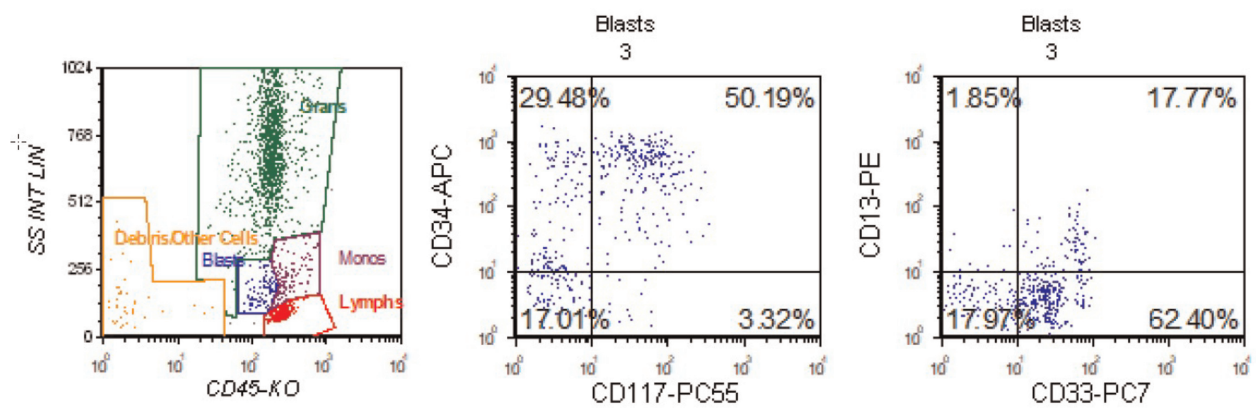

Figure 1. Flow cytometry. Peripheral blood flow cytometry showed a $\mathrm{CD} 34^{+}$myeloid blast population that expressed CD33, CD117, CD38, HLA-DR, and CD7 (partial) was identified. B cells constituted $4 \%$ of lymphocytes and had a $\kappa: \lambda$ ratio of 1.0 . T cells comprised $92 \%$ of lymphocytes and had normal expression of T-cell antigens, with a CD4:CD8 ratio of 5.6 .

$72,000 / \mu \mathrm{L}$. Neonatal alloimmune thrombocytopenia (NAIT) was the working diagnosis for his thrombocytopenia. Confirmatory testing was performed and there was a mismatch between parental and maternal platelet antigens (PLA-3b); however, there were no antibodies identified ruling out NAIT. In searching for other etiologies, flow cytometry performed on the initial blood sample obtained on the day of life 1 identified a small population, $3.4 \%$ of total analyzed cells of $\operatorname{dim}$ CD34/blasts positive cells (see Fig. 1). The CD34 $4^{+}$myeloid blast population expressed CD33, CD117, CD38, HLA-DR, and CD7 (partial). Between days of life 3 and 8 serial CBCs with manual peripheral blood smears identified peripheral blasts and early myeloid precursors, peaking at $4 \%$ blasts. He remained clinically well without constitutional symptoms, hepatosplenomegaly, respiratory distress, or leukemia cutis. Possible etiologies of thrombocytopenia and peripheral blasts/myeloid precursors in a neonate include neonatal leukemia or transient myeloproliferative disorder (TMD) (Ansari et al. 2015; Khan et al. 2018; Kurzer and Weinberg 2019).

Because TMD is universally associated with trisomy 21 , we considered the possibility of potential low-level or tissue-specific mosaicism missed by prenatal screening, targeted interphase fluorescence in situ hybridization (FISH) testing for Chromosome 21 was performed on an uncultured blood sample, with a sample containing $0 \%$ blasts in the peripheral blood. Results confirmed mosaic trisomy 21 in 22.5\% (45/200 interphase cells). The PHA-stimulated blood sample from this patient demonstrated $\operatorname{mos} 47, \mathrm{XY},+21[1] / 46, \mathrm{XY}[4]$.nuc ish $(\mathrm{RB} 1 \times 2$, D21S259/D21S341/D21S342 × 3)[43/200] similar to the uncultured specimen, suggesting constitutional mosaicism for trisomy 21 (see Table 1). However, further testing on other tissues has not been done to date. The association of TMD and trisomy 21 was discussed with the primary team and considered yet the neonate did not have any clinical features of Down syndrome. Moreover, NIPS, which is testing on cell-free fetal DNA in maternal circulation, had been negative. This individual may have either trisomy 21 mosaicism limited to hematopoietic cells, or low-level mosaicism more broadly that is insufficient to lead to other manifestations of Down syndrome.

Table 1. Cytogenetic results of peripheral blood cells

\begin{tabular}{lll}
\hline Culture conditions & Interphase FISH & \multicolumn{1}{c}{ Karyotype } \\
\hline Unstimulated & Trisomy 21 in 22.5\% & - \\
PHA-stimulated $^{\text {a }}$ & Trisomy 21 in 21.5\% & Limited cell division-25\% trisomy 21 \\
\hline
\end{tabular}

${ }^{a}$ Enhances growth of T-lymphocytes. 
A myeloid next-generation sequencing (NGS) panel, including GATA1 (only exon 2 sequencing) and $K R A S$, found no clinically significant variants. Low levels of blasts were identified on days 3-8 of life (3\%-4\% blasts) and then self-resolved. The thrombocytopenia and mild polycythemia resolved by $\sim 2.5$ and 3.5 wk of life, respectively. He had no evidence of hepatic or respiratory involvement at any time. Given the cytogenetic results of trisomy 21 mosaicism in hematopoietic cells, an echocardiogram was performed and was normal except for a patent foramen ovale (left-to-right shunting). Thyroid testing was also normal. At the time of this report, the patient is currently 5 mo of age without evidence of recurrent disease. He will undergo follow-up monthly for the first year of life, then every 3 mo until age 3 , and then every 6 mo until 4 yr of age.

\section{TECHNICAL ANALYSIS}

Cytogenetic analyses were performed on phytohemagglutinin (PHA)-stimulated blood, and FISH for Chromosome 21 on both the uncultured and cultured blood was performed using a commercially available probe set (Abbott Molecular Inc.). A myeloid NGS panel using the Archer Myeloid VariantPlex panel with copy-number detection was performed on a peripheral blood sample. GATA1 coverage was limited to exon 2 (GRCh37 Chr X: 4864949748649756), and the depth of coverage for this sample was $300 \times$. Director review of all variants in this region was performed at a variant allele fraction of $2 \%$.

\section{SUMMARY}

This child apparently has a mosaic trisomy 21 patient presenting with only TMD and no other recognizable features of Down syndrome. Because of the limited available testing data we cannot further assess the extent of trisomy 21 mosaicism - we only know that it was present in the TMD blast cells but absent on NIPS. When a patient has a myeloid disorder, it is recommended that germline testing be performed on cultured fibroblasts to assess chromosomal or mutational events that may not be limited to the hematopoietic compartment.

It is known that varying degrees of mosaicism for trisomy 21 exist in apparently healthy individuals; however, it is difficult to know the prevalence because there are few data on this population (Dagna Bricarelli et al. 1990; Pham et al. 2014; Papavassiliou et al. 2015). Of course, mosaicism varies among tissues, and therefore negative results in any one cell type cannot exclude mosaicism in other cell types, tissue, organs, or body segments (Kowalczyk et al. 2007; Biesecker and Spinner 2013).

Although NIPS has $99.3 \%$ sensitivity for trisomy 21 (Taylor-Phillips et al. 2016), mosaicism in the fetus can reduce this sensitivity (Health Quality Ontario 2019; Neofytou 2020). The fetal cell-free DNA assayed in NIPS is primarily from trophoblastic cells. If mosaicism occurs by mitotic nondisjunction later in development leading to tissue limited mosaicism, the placenta would be spared, resulting in a false-negative NIPS (Levy et al. 2021).

Between $4 \%$ and $10 \%$ of newborns with trisomy 21 develop TMD, which is a rare clonal myeloproliferative disorder associated with a varied clinical course (Zipursky et al. 1997; Bajwa et al. 2004; Pine et al. 2007; Gamis et al. 2011). Many individuals with TMD have spontaneous resolution, but there are fatal outcomes in severe cases (Gamis et al. 2011; Watanabe 2019). Overall, children with Down syndrome up to age 4 yr are at a 150-fold excess risk of developing myeloid leukemia (ML-DS) (Alford et al. 2011). Individuals with a history of TMD have a 20\%-30\% risk of developing ML-DS by age 4 and require close monitoring (Homans et al. 1993; Massey et al. 2006; Gamis et al. 2011). Blast cell structure and immunophenotype are similar in TMD and ML-DS with a mutation in the hematopoietic 
transcription factor GATA1 being present in almost all cases (Alford et al. 2011). This patient did not have a GATA1 mutation identified in exon 2. Although GATA1 exon 2 is the most recurrent region altered in DS-TMD (Alford et al. 2011), variants outside of this region have been reported in DS-TMD (Alford et al. 2011). Additionally, the blast count was extremely low, which may lead to a false negative by NGS because of the limit of detection.

There are other reports of newborns with TMD without other clinical features of Down syndrome who had mosaic trisomy 21 in blood and bone marrow at diagnosis (Bhatt et al. 1995; Rozen et al. 2014; Prudowsky et al. 2020). In some of these reports, the mosaicism persisted after the TMD had resolved (Bhatt et al. 1995), but in others, once the TMD has resolved, trisomy 21 could not be identified in the blood (Rozen et al. 2014; Prudowsky et al. 2020).

Trisomy 21 mosaicism remains a relevant diagnostic consideration in individuals with TMD, even in the absence of recognizable features of Down syndrome. Individuals with mosaic trisomy 21 , depending on which tissues are affected by the trisomy, have an increased risk of neonatal TMD and acute leukemias in childhood and adolescence, but also possibly protection from some solid tumors (Hultén et al. 2010). Furthermore, outside of TMD, individuals with trisomy 21 are at increased risk for other hematological malignancies, such as acute lymphoblastic leukemia and acute megakaryoblastic leukemia (Chisholm 2017; Laurent et al. 2020; Won et al. 2020). Constitutional mosaicism can be difficult to prove, especially in the setting of hematopoietic abnormalities; therefore, further testing is warranted in this patient population.

Trisomy 21, either constitutional or mosaic, and perhaps even limited to the hematopoietic compartment, is essentially universal in TMD. Individuals who present with TMD should be evaluated for trisomy 21 even when recognizable features or Down syndrome are absent and when prenatal screening is negative. Demonstrating the extent of the mosaicism is vital to understanding further risks and additional screening important for patient care.

\section{ADDITIONAL INFORMATION}

\section{Data Deposition and Access}

The case presented did not have any sequence variants to report.

\section{Ethics Statement}

Our Institutional Review Board does not require review or consent for case reports with no identifying information.

\section{Acknowledgments}

The authors thank the medical staff who participated in this patient's care.

The authors have declared no competing interest.

\section{Referees}

Mary B. Callanan

Anonymous

Received June 30, 2021; accepted in revised form November 16, 2021.

\section{Author Contributions}

N.B. conceived and designed the study. Sample acquisition, preparation, and sequencing were performed by F.M., C.E., and R.S. The data were analyzed by C.E. and R.S. Administrative, technical, or material support was provided by N.B., C.E., and R.S. The study was supervised by all the authors. The drafting and revision of the manuscript were done by all authors. All authors have read and agreed to the published version of the manuscript. 


\section{REFERENCES}

Alford KA, Reinhardt K, Garnett C, Norton A, Böhmer K, von Neuhoff C, Kolenova A, Marchi E, Klusmann JH, Roberts I, et al. 2011. Analysis of GATA1 mutations in Down syndrome transient myeloproliferative disorder and myeloid leukemia. Blood 118: 2222-2238. doi:10.1182/blood-2011-03-342774

Ansari DO, Lapping-Carr G, Alikhan M, Tsoukas ML, Stein SL, de Jong JL. 2015. A neonate with a vesiculopustular rash. Pediatr Ann 44: e1-e5. doi:10.3928/00904481-20151226-07

Bajwa RP, Skinner R, Windebank KP, Reid MM. 2004. Demographic study of leukaemia presenting within the first 3 months of life in the Northern Health Region of England. J Clin Pathol 57: 186-188. doi:10.1136/jcp .2003 .12039

Bhatt S, Schreck R, Graham JM, Korenberg JR, Hurvitz CG, Fischel-Ghodsian N. 1995. Transient leukemia with trisomy 21: description of a case and review of the literature. Am J Med Genet 58: 310-314. doi:10.1002/ ajmg.1320580404

Biesecker LG, Spinner NB. 2013. A genomic view of mosaicism and human disease. Nat Rev Genet 14: 307320. doi:10.1038/nrg3424

Chisholm KM. 2017. Acute lymphoblastic leukemia in Down syndrome. Atlas Genet Cytogenet Oncol Haematol 341-345. doi:10.4267/2042/68933

Dagna Bricarelli F, Pierluigi M, Grasso P, Strigini P, Perroni L. 1990. Origin of extra Chromosome 21 in 343 families: cytogenetic and molecular approaches. Am J Med Genet Suppl 7: 129-132. doi:10.1002/ajmg .1320370726

Gamis AS, Alonzo TA, Gerbing RB, Hilden JM, Sorrell AD, Sharma M, Loew TW, Arceci RJ, Barnard D, Doyle J, et al. 2011. Natural history of transient myeloproliferative disorder clinically diagnosed in Down syndrome neonates: a report from the Children's Oncology Group Study A2971. Blood 118: 6752-6759. doi:10 .1182/blood-2011-04-350017

Health Quality Ontario. 2019. Noninvasive prenatal testing for trisomies 21, 18, and 13, sex chromosome aneuploidies, and microdeletions: a health technology assessment. Ont Health Technol Assess Ser 19: 1-166.

Homans AC, Verissimo AM, Vlacha V. 1993. Transient abnormal myelopoiesis of infancy associated with trisomy 21. Am J Pediatr Hematol Oncol 15: 392-399.

Hultén MA, Jonasson J, Nordgren A, Iwarsson E. 2010. Germinal and somatic trisomy 21 mosaicism: how common is it, what are the implications for individual carriers and how does it come about? Curr Genomics 11: 409-419. doi:10.2174/138920210793176056

Khan M, Siddiqi R, Naqvi K. 2018. An update on classification, genetics, and clinical approach to mixed phenotype acute leukemia (MPAL). Ann Hematol 97: 945-953. doi:10.1007/s00277-018-3297-6

Kowalczyk M, Srebniak M, Tomaszewska A. 2007. Chromosome abnormalities without phenotypic consequences. J Appl Genet 48: 157-166. doi:10.1007/BF03194674

Kurzer JH, Weinberg OK. 2019. Acute leukemias of ambiguous lineage: clarification on lineage specificity. Surg Pathol Clin 12: 687-697. doi:10.1016/j.path.2019.03.008

Laurent AP, Kotecha RS, Malinge S. 2020. Gain of Chromosome 21 in hematological malignancies: lessons from studying leukemia in children with Down syndrome. Leukemia 34: 1984-1999. doi:10.1038/ s41375-020-0854-5

Levy B, Hoffmann ER, McCoy RC, Grati FR. 2021. Chromosomal mosaicism: origins and clinical implications in preimplantation and prenatal diagnosis. Prenat Diagn 41: 631-641. doi:10.1002/pd.5931

Massey GV, Zipursky A, Chang MN, Doyle JJ, Nasim S, Taub JW, Ravindranath Y, Dahl G, Weinstein HJ. 2006. A prospective study of the natural history of transient leukemia (TL) in neonates with Down syndrome (DS): Children's Oncology Group (COG) study POG-9481. Blood 107: 4606-4613. doi:10.1182/blood-2005-06-2448

Neofytou M. 2020. Predicting fetoplacental mosaicism during cfDNA-based NIPS. Curr Opin Obstet Gynecol 32: 152-158. doi:10.1097/GCO.0000000000000610

Papavassiliou P, Charalsawadi C, Rafferty K, Jackson-Cook C. 2015. Mosaicism for trisomy 21: a review. Am J Med Genet A 167a: 26-39. doi:10.1002/ajmg.a.36861

Pham J, Shaw C, Pursley A, Hixson P, Sampath S, Roney E, Gambin T, Kang SH, Bi W, Lalani S, et al. 2014. Somatic mosaicism detected by exon-targeted, high-resolution aCGH in 10,362 consecutive cases. Eur J Hum Genet 22: 969-978. doi:10.1038/ejhg.2013.285

Pine SR, Guo Q, Yin C, Jayabose S, Druschel CM, Sandoval C. 2007. Incidence and clinical implications of GATA1 mutations in newborns with Down syndrome. Blood 110: 2128-2131. doi:10.1182/blood-200701-069542

Prudowsky Z, Han H, Stevens A. 2020. Transient abnormal myelopoeisis and mosaic down syndrome in a phenotypically normal newborn. Children (Basel) 7: 52. doi:10.3390/children7060052

Rozen L, Huybrechts S, Dedeken L, Heijmans C, Dessars B, Heimann P, Lambert F, Noubouossie DF, Ferster A, Demulder A. 2014. Transient leukemia in a newborn without Down syndrome: case report and review of the literature. Eur J Pediatr 173: 1643-1647. doi:10.1007/s00431-013-2163-8 
Taylor-Phillips S, Freeman K, Geppert J, Agbebiyi A, Uthman OA, Madan J, Clarke A, Quenby S, Clarke A. 2016. Accuracy of non-invasive prenatal testing using cell-free DNA for detection of Down, Edwards and Patau syndromes: a systematic review and meta-analysis. BMJ Open 6: e010002. doi:10.1136/ bmjopen-2015-010002

Watanabe K. 2019. Recent advances in the understanding of transient abnormal myelopoiesis in Down syndrome. Pediatr Int 61: 222-229. doi:10.1111/ped.13776

Won E, Gruber TA, Tucker S, Schiff DE. 2020. Acute megakaryoblastic leukemia with trisomy 21 and tetrasomy 21 clones in a phenotypically normal child with mosaic trisomy 21. Case Rep Pediatr 2020: 7813048. doi:10 $.1155 / 2020 / 7813048$

Zipursky A, Brown E, Christensen H, Sutherland R, Doyle J. 1997. Leukemia and/or myeloproliferative syndrome in neonates with Down syndrome. Semin Perinatol 21: 97-101. doi:10.1016/S0146-0005(97) 80025-0 


\section{COLD SPRING HARBOR Molecular Case Studies}

\section{Transient myeloproliferative disorder as the presenting feature for mosaic trisomy 21}

Nicole Baca, Pedro A. Sanchez-Lara, Rhona Schreck, et al.

Cold Spring Harb Mol Case Stud 2021, 7: a006126 originally published online November 17, 2021 Access the most recent version at doi: $10.1101 / \mathrm{mcs} .0006126$

References This article cites 27 articles, 6 of which can be accessed free at: http://molecularcasestudies.cshlp.org/content/7/6/a006126.full.html\#ref-list-1

License This article is distributed under the terms of the Creative Commons Attribution-NonCommercial License, which permits reuse and redistribution, except for commercial purposes, provided that the original author and source are credited.

Email Alerting Receive free email alerts when new articles cite this article - sign up in the box at the Service top right corner of the article or click here. 